\title{
Bufalin suppresses tumour microenvironment-mediated angiogenesis by inhibiting the STAT3 signalling pathway
}

Kai Fang ${ }^{1,2,3,4+}$, Yueping Zhan ${ }^{1,3+}$, Ruiqiu Zhu ${ }^{1,3,4+}$, Yuqian Wang ${ }^{1,3}$, Chengqi Wu ${ }^{1,2,3,4}$, Min Sun ${ }^{1}$, Yanyan Qiu ${ }^{1,3}$, Zeting Yuan ${ }^{1,3,5}$, Xin Liang ${ }^{4^{*}}$, Peihao Yin $^{1,3,5^{*}}$ and $\mathrm{Ke} \mathrm{Xu}^{2,3,5,6^{*}}$

\begin{abstract}
Background: Antiangiogenic therapy has increasingly become an important strategy for the treatment of colorectal cancer. Recent studies have shown that the tumour microenvironment (TME) promotes tumour angiogenesis. Bufalin is an active antitumour compound whose efficacy has been indicated by previous studies. However, there are very few studies on the antiangiogenic effects of bufalin.
\end{abstract}

Methods: Herein, human umbilical vein endothelial cell (HUVEC) tube formation, migration and adhesion tests were used to assess angiogenesis in vitro. Western blotting and quantitative PCR were used to detect relevant protein levels and mRNA expression levels. A subcutaneous xenograft tumour model and a hepatic metastasis model were established in mice to investigate the influence of bufalin on angiogenesis mediated by the TME in vivo.

Results: We found that angiogenesis mediated by cells in the TME was significantly inhibited in the presence of bufalin. The results demonstrated that the proangiogenic genes in HUVECS, such as VEGF, PDGFA, E-selectin and P-selectin, were downregulated by bufalin and that this downregulation was mediated by inhibition of the STAT3 pathway. Overexpression of STAT3 reversed the inhibitory effects of bufalin on angiogenesis. Furthermore, there was little reduction in angiogenesis when bufalin directly acted on the cells in the tumour microenvironment.

Conclusion: Our findings demonstrate that bufalin suppresses tumour microenvironment-mediated angiogenesis by inhibiting the STAT3 signalling pathway in vascular endothelial cells, revealing that bufalin may be used as a new antiangiogenic adjuvant therapy medicine to treat colorectal cancer.

Keywords: Angiogenesis, Bufalin, Colorectal cancer, STAT3, Tumour microenvironment

*Correspondence: xin.liang@ecust.edu.cn; yinpeihao@shutcm.edu.cn; cola519@163.com; kexu@shu.edu.cn

${ }^{\dagger}$ Kai Fang, Yueping Zhan and Ruiqiu Zhu contributed equally to this study

${ }^{1}$ Putuo Hospital, Shanghai University of Traditional Chinese Medicine,

Shanghai 200062, China

${ }^{2}$ Institute of Translational Medicine, Shanghai University,

Shanghai 200444, China

${ }^{4}$ State Key Laboratory of Bioreactor Engineering \& Shanghai Key Laboratory of New Drug Design, School of Pharmacy, East China

University of Science and Technology, 130 Meilong Rd, Shanghai 200237, China

Full list of author information is available at the end of the article

\section{Background}

Colorectal cancer (CRC) is the third most common cancer worldwide and accounts for $9 \%$ of all cancerrelated deaths [1], and its incidence is increasing. It is now widely accepted that angiogenesis plays a key role in tumour development, progression and metastasis [2]. Abnormal angiogenesis is a hallmark of solid tumours [3]. The concept of antiangiogenic therapy arose from the seminal observations by Judah Folkman and colleagues. It has been reported that antiangiogenic therapy can effectively improve the survival rate of CRC patients, which original author(s) and the source, provide a link to the Creative Commons licence, and indicate if changes were made. The images or other third party material in this article are included in the article's Creative Commons licence, unless indicated otherwise in a credit line to the material. If material is not included in the article's Creative Commons licence and your intended use is not permitted by statutory regulation or exceeds the permitted use, you will need to obtain permission directly from the copyright holder. To view a copy of this licence, visit http://creativecommons.org/licenses/by/4.0/. The Creative Commons Public Domain Dedication waiver (http://creativeco mmons.org/publicdomain/zero/1.0/) applies to the data made available in this article, unless otherwise stated in a credit line to the data. 
indicates that inhibiting tumour angiogenesis is a potential method for treating CRC [4-7].

Many studies have demonstrated that the TME including the cancer-associated fibroblasts (CAFs) and tumourassociated macrophages (TAMs) contained within it, promotes tumour angiogenesis [8-10]. The tumour microenvironment, which is also termed the tumour mesenchyme or tumour stroma, includes CAFs, TAMs, blood vessels and extracellular matrix and substantially influences the initiation, growth and dissemination of CRC [3]. Signal transducer and activator of transcription 3 (STAT3) belongs to a family of transcription factors that regulate the expression of genes involved in the pathogenesis of many human malignancies [11, 12]. It was also reported that the TME activates STAT3 signalling in human umbilical vein endothelial cells [13], and that the tumour microenvironment may affect angiogenesis through the STAT3 signalling pathway. In summary, the STAT3 pathway in blood vessels may become a target for the treatment of angiogenesis.

Bufalin (BU), the major bioactive component isolated from toad venom (Fig. 1a), has been confirmed to be a potent antitumour drug due to its effects on tumour cell apoptosis, metastasis and proliferation [14, 15]. In addition, bufalin inhibits angiogenesis, and it was reported that the antiangiogenic effects of sorafenib were significantly increased when used in combination with bufalin by targeting AKT/VEGF in HUVECs [16]. Wu et al. showed that bufalin enhanced cytocidal effects by targeting the STAT3 pathway [17].

Previously, we performed numerous studies on bufalin for the treatment of colorectal cancer [14, 18, 19]. Here, we found that bufalin could reverse the proangiogenic effects mediated by the TME. In the present study, we used in vitro angiogenesis-related experiments, an in vivo subcutaneous tumour model and an in vivo liver metastasis model to demonstrate that bufalin can inhibit TMEmediated STAT3 activation in endothelial cells to reduce angiogenesis, identifying a new mechanism of action of bufalin in the treatment of CRC.

\section{Materials and methods}

\section{Cell culture}

Cells were cultured in a humidified incubator with an atmosphere of $5 \% \mathrm{CO}_{2}$ at $37{ }^{\circ} \mathrm{C}$ under normal oxygen conditions. Human umbilical vein endothelial cells (HUVECs; \#8000, ScienCell, USA) were grown in endothelial cell medium (ECM; \#1001, ScienCell, USA), and only early passages $(<\mathrm{p} 6)$ were used. CT26 cells were obtained from the Cell Bank of the Chinese Academy of Sciences and were cultured in RPMI-1640 containing 10\% FBS and 1\% penicillin/streptomycin. The STAT3 overexpression plasmid was purchased from GeneChem (Shanghai, CN).

\section{Conditioned medium (CM) preparation}

CT26 cells were confirmed by morphological observation (Additional file 1: Fig. S1a) and WB (Additional file 1: Fig. $\mathrm{S} 1 \mathrm{~b})$. The tumour cell supernatant polarized the M0 macrophages, which was confirmed by morphological observation and flow cytometry (Additional file 1: Fig. S1c, d). When TAMs, CAFs or CT26 cells grew to $80 \%$ confluence, the medium was replaced with FBS-free medium. After $48 \mathrm{~h}$ of treatment, cell suspensions were collected as the CM. The CM was collected after high-speed centrifugation and then filtered through a $0.22 \mu \mathrm{m}$ microporous membrane and stored at $-20{ }^{\circ} \mathrm{C}$. In the same way, the cells were treated with $10 \mathrm{nM}$ bufalin for $24 \mathrm{~h}$ and then treated as described above to obtain the relevant conditioned medium after drug treatment.

\section{Tube formation assay}

HUVECs were incubated with conditioned medium for $24 \mathrm{~h}$ before the tube formation assay. Matrigel (BD, \#356234, USA) was thawed overnight at $4{ }^{\circ} \mathrm{C}$, and $50 \mu \mathrm{l}$ of Matrigel was spread in a 96-well plate and polymerized at $37{ }^{\circ} \mathrm{C}$ for $30 \mathrm{~min}$. Next, $3 \times 10^{4}$ HUVECs in $50 \mu \mathrm{l}$ of ECM were seeded into each well for incubation at $37^{\circ} \mathrm{C}$ in $5 \% \mathrm{CO}_{2}$ for $4 \mathrm{~h}$. HUVECs were photographed under a microscope.

\section{Cell migration assay}

HUVECs were incubated with conditioned medium for $24 \mathrm{~h}$ before the migration assay. HUVECs $\left(3 \times 10^{4}\right)$ in $300 \mu \mathrm{l}$ of serum-free ECM were added to the upper chamber $(8.0 \mu \mathrm{m}$ pore size, \#353,097, FALCON, USA), and allowed to migrate towards $700 \mu$ of complete ECM. The unmigrated cells were removed from the upper part of the Transwell chamber with a cotton swab after $6 \mathrm{~h}$ of incubation, and the insert was fixed with $4 \%$ paraformaldehyde for $10 \mathrm{~min}$ at room temperature. The Transwell inserts were stained with $500 \mu \mathrm{l}$ of $0.03 \%$ crystal violet solution for $30 \mathrm{~min}$ at $37^{\circ} \mathrm{C}$. Then, the insert was immersed in PBS and washed three times with PBS for 5 min each time, and then dried and photographed under a microscope.

\section{Adhesion assay}

HUVECs were seeded in a 24-well plate and then treated with conditioned medium for $24 \mathrm{~h}$. HCT116-GFP cells $\left(2 \times 10^{4}\right)$ in $300 \mu \mathrm{l}$ of serum-free ECM were coincubated with the treated HUVECs for incubation at $37^{\circ} \mathrm{C}$ for $2 \mathrm{~h}$. Cells were washed with PBS three times and then photographed under a fluorescence microscope. 


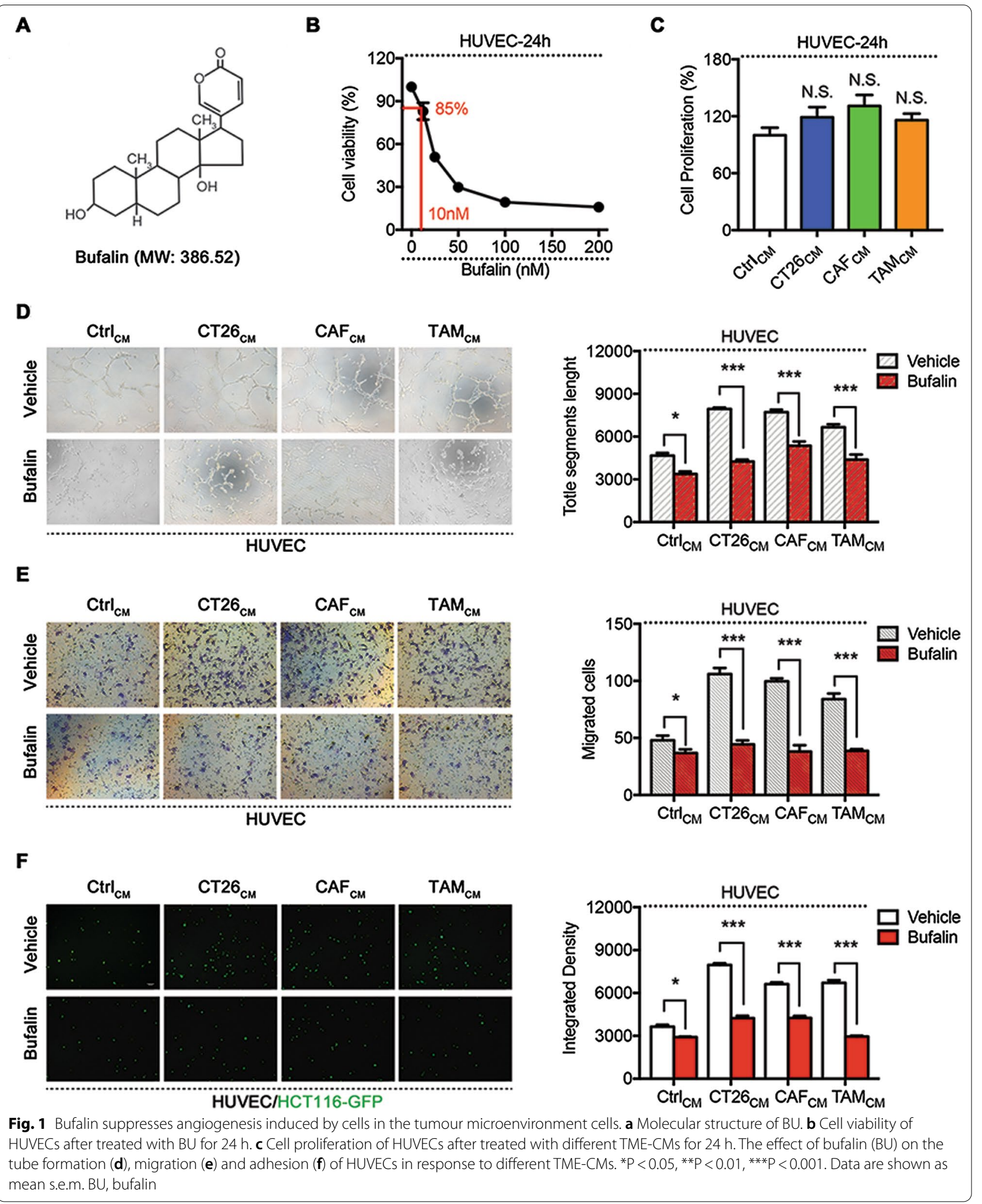




\section{Quantitative PCR}

Total RNA was extracted from HUVECs using TRIzol (Invitrogen). The concentration of total RNA was quantified by measuring the absorbance at $260 \mathrm{~nm}$. For SYBR Green-based quantitative PCR amplification, the reaction was carried out in a volume of $20 \mu \mathrm{l}$ (Applied Biosystems). The $2^{-\Delta \Delta C t}$ method was used to determine the relative expression level of each cell line in each group.

The primer sequences were as follows: VEGF, $5^{\prime}$-TTG CTGCTCTACCTCCAC-3' and 5'-AATGCTTTCTCC GCTCTG-3'; PDGFA, 5'-AGGCGTCCAGGCAGG TGATC- $3^{\prime}$ and $5^{\prime}$-GCTTCTTCCTCGGTGCGTTCC3'; E-selectin, 5'-ATGTTCAAGCCTGGCAGTTCCG$3^{\prime}$ and $5^{\prime}$-GCAGAGCCATTGAGCGTCCATC-3'; and P-selectin, $\quad 5^{\prime}$-CGCTCTGGACCAACCCTGTTTC- ${ }^{\prime}$ and $5^{\prime}$-CTCCTGGCTTCTGTGGCTTGTG-3'.

\section{Western blot (WB)}

The proteins were separated by SDS-PAGE. After incubation with blocking solution (5\% nonfat dry milk in PBST) for $1 \mathrm{~h}$ at room temperature, the membranes were exposed to primary antibodies overnight at $4{ }^{\circ} \mathrm{C}$ (VEGF, Abcam, ab46154, rabbit IgG), (P-STAT3, CST, 4113S, mouse IgG), (STAT3, CST, 9139S, mouse IgG), (E-cadherin, CST, 3195S, rabbit IgG), (Vimentin, CST, 5741S, rabbit IgG), ( $\alpha$-SMA, Sigma, A2547, mouse IgG), and ( $\beta$-actin, Abcam, ab6276, mouse IgG). The membranes were further probed with horseradish peroxidase-conjugated anti-rabbit/mouse IgG antibody (CST, 1:5000). ImageJ software was used to quantify the protein bands.

\section{In vivo xenograft model}

To determine the antiangiogenic activity of bufalin in vivo, CT26-LUC cells $\left(2 \times 10^{6}\right)$ were injected subcutaneously or into the spleens of male BALB/c mice (6 weeks old). 1 week after injection, bufalin $(1 \mathrm{mg} / \mathrm{kg})$ was administered by intraperitoneal (i.p.) injection once every other day for 21 days (flank) or 14 days (spleen). The vehicle group was treated with normal saline. Subcutaneous tumour sizes were measured every 3 days, and live imaging was performed once a week after treatment. The estimated tumour volume $(\mathrm{V})$ was calculated by the Formula $\mathrm{V}=\mathrm{W}^{2} \times \mathrm{L} \times 0.5$, where $\mathrm{W}$ represents the largest tumour diameter in centimetres and $L$ represents the next largest tumour diameter. Tumour-bearing mice were sacrificed after 21 or 14 days of treatment, and the tumour tissues, spleens and livers were harvested, weighed, and immediately fixed in formalin for follow-up experiments.

All experiments conformed to the ethical principles of animal experimentation stipulated by the Institutional Animal Care and Use Committee of Putuo Hospital, Shanghai University of Traditional Chinese Medicine, China.

\section{Histopathological assay}

Tissues were harvested after the animals were sacrificed. The histopathological assay procedure was carried out by conventional haematoxylin-eosin (H\&E) staining in accordance with standard techniques.

\section{Immunofluorescence}

HUVECs $\left(2 \times 10^{4}\right)$ were seeded and cultured overnight on microscope coverslips (Thermo Fisher Scientific, Waltham, MA, USA). After treatment with CM with or without bufalin for $24 \mathrm{~h}$ as described previously, the cells were washed with PBS twice, fixed in methanol for 15 min, permeabilized with $0.2 \%$ Triton X-100 (Beyotime, Shanghai, China)/PBS for 5 min and blocked with $5 \% \mathrm{BSA}$ for $1 \mathrm{~h}$ at room temperature. The coverslips were incubated with primary antibodies at $4{ }^{\circ} \mathrm{C}$ overnight (p-STAT3, CST, 4113S, mouse IgG) and (CD31, Abcam, ab28364, rabbit IgG) and then incubated with secondary antibodies for $2 \mathrm{~h}$ at $37^{\circ} \mathrm{C}$ protected from light (goat antimouse IgG H\&L (Alexa Fluor ${ }^{\circledR} 488$ ), Abcam, ab150113) and (goat anti-rabbit IgG H\&L (Alexa Fluor ${ }^{\circledR}$ 594), Abcam, ab150080). Nuclear localization was assessed with 4',6-diamidino-2-phenylindole (DAPI; Beyotime, Shanghai, China).

Tissue sections were permeabilized with cold methanol for 5 min and incubated with 5\% BSA in PBS for $1 \mathrm{~h}$. Primary antibodies were applied in blocking buffer and incubated overnight at $4{ }^{\circ} \mathrm{C}$. Dye-conjugated secondary antibodies were added to the blocking buffer and incubated for $2 \mathrm{~h}$. Nuclei were stained with 4',6-diamidino2-phenylindole (DAPI; Beyotime, Shanghai, China). Images were acquired using a Zeiss LSM880 confocal microscope at the same voltage level and analysed using ZEN Software.

\footnotetext{
(See figure on next page.)

Fig. 2 Bufalin suppresses TME-mediated angiogenesis by inhibiting angiogenic factors. Relative PDGFA, VEGF, E-selectin and P-selectin mRNA expression in HUVECs after treatment with CT26-CM (a), CAF-CM (b) or TMA-CM (c) with or without bufalin (BU). d-f WB showing the protein expression of VEGF, p-STAT3 and STAT3 in HUVECs treated with different TME-CMs in the presence or absence of BU, with total $\beta$-actin as a control. $\mathbf{g - i}$ The concentration of VEGFA in HUVECs supernatant after treatment with different TME-CMs in the presence or absence of BU. $\mathbf{j}$ Immunofluorescence analysis showing p-STAT3 ${ }^{+}$HUVECs after treatment with different TME-CMs in the presence or absence of BU. ${ }^{*} P<0.05$, ${ }^{* *} \mathrm{P}<0.01,{ }^{* *} \mathrm{P}<0.001$. Data are shown as mean s.e.m. BU, bufalin
} 
(A)

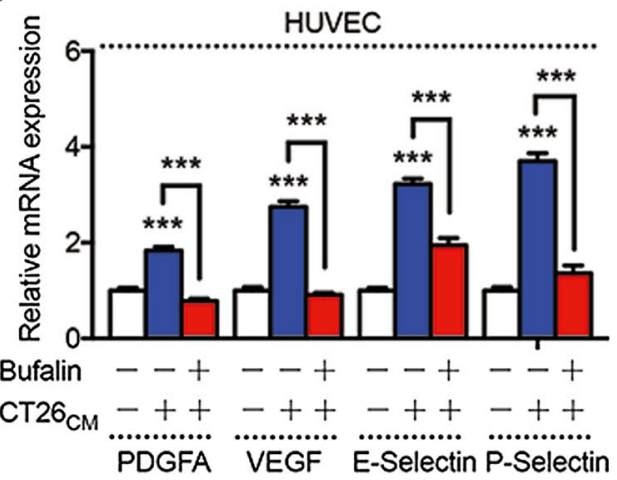

(B)

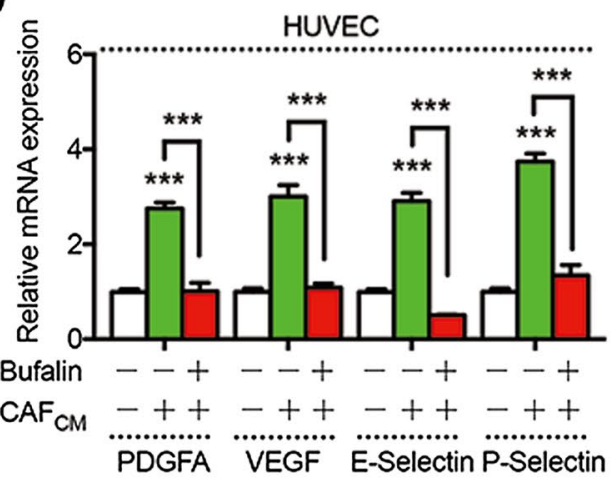

(C)

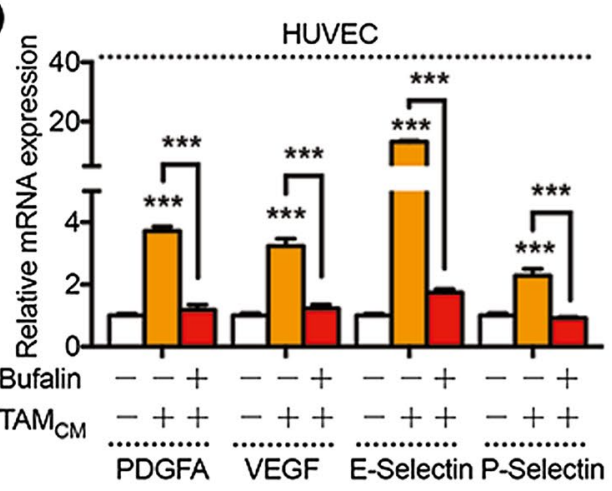

(D)

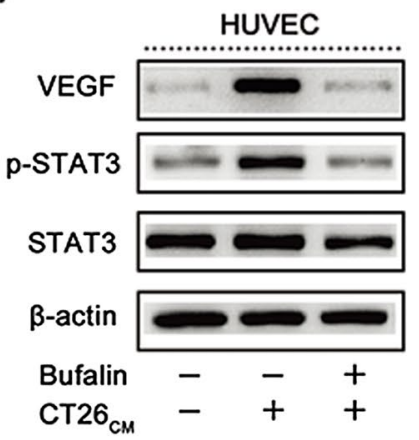

(E)

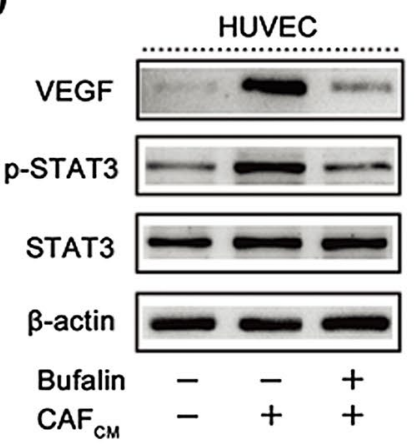

(F)

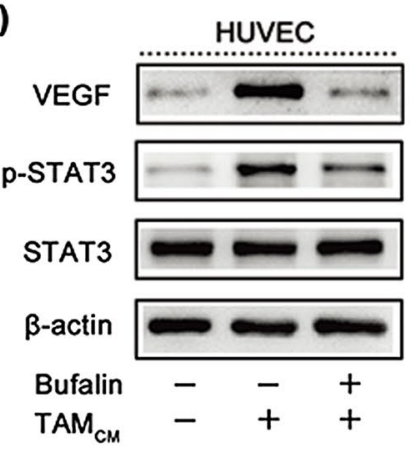

(H)

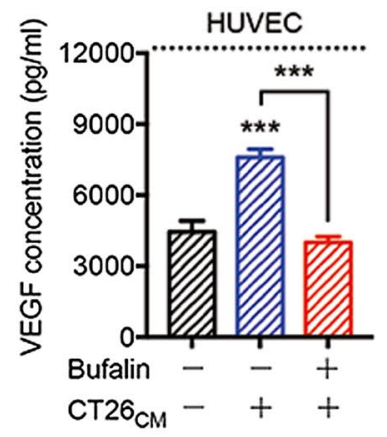

(I)

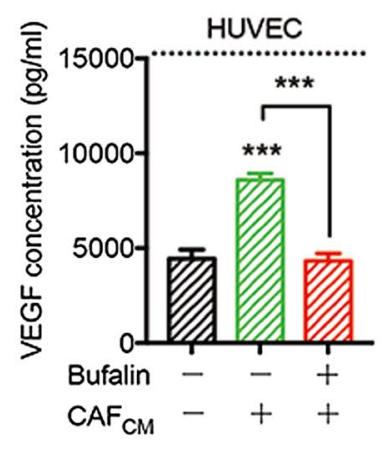

(J)

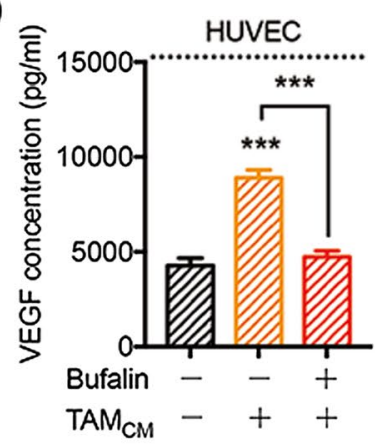

(G)

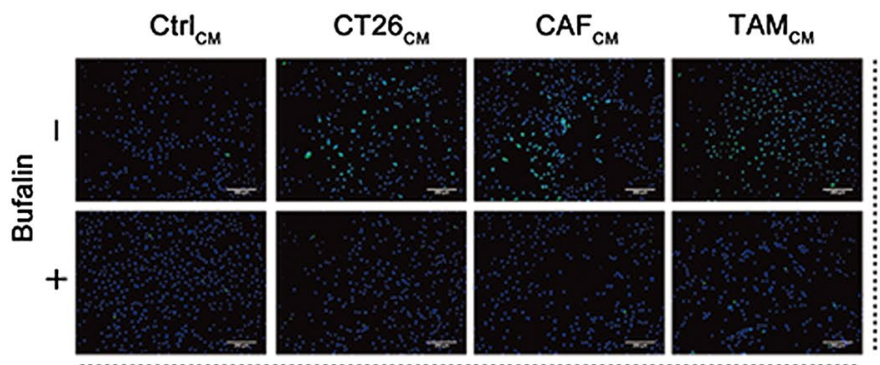

DAPI/P-STAT3

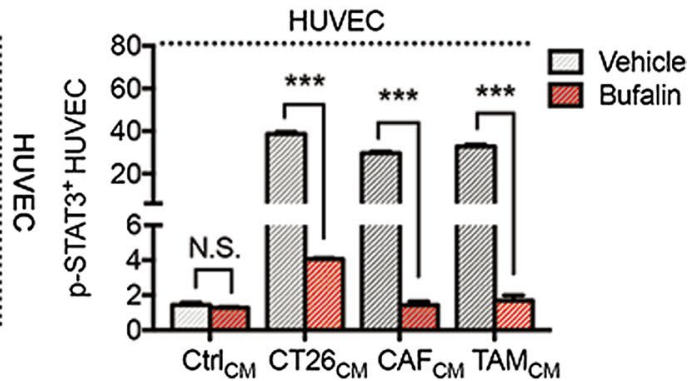

Fig. 2 (See legend on previous page.) 
(A)
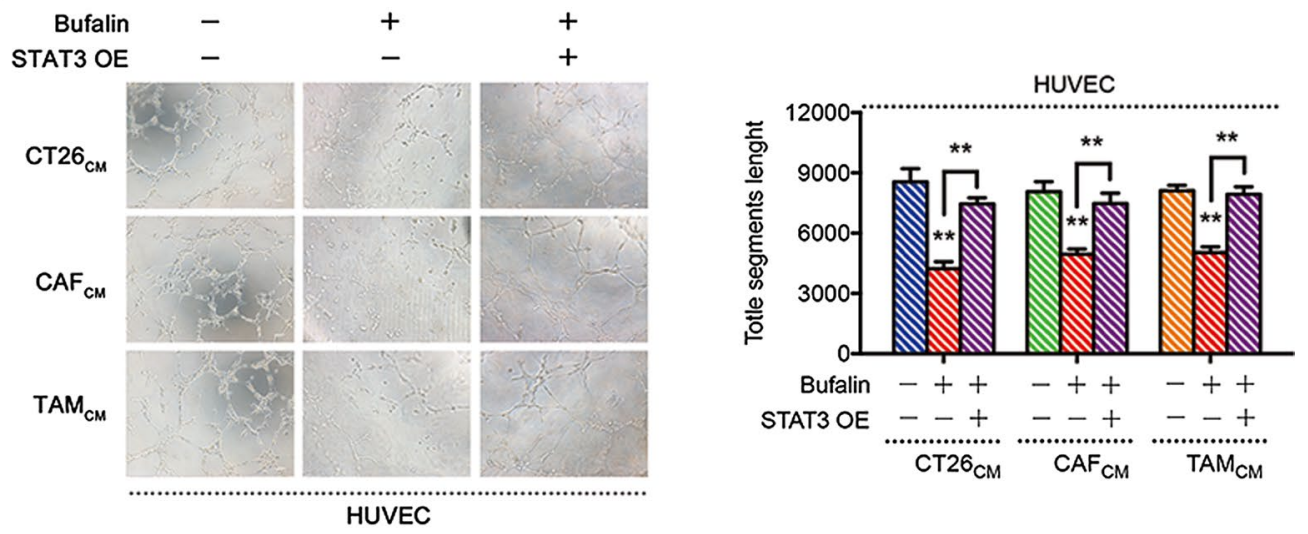

(B)
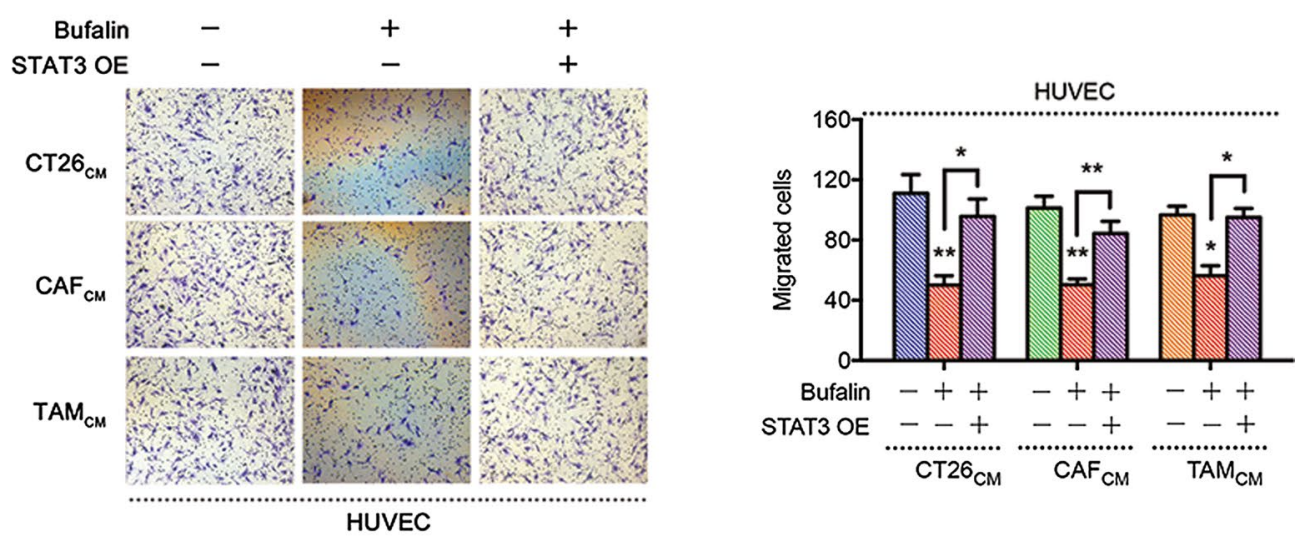

(C)
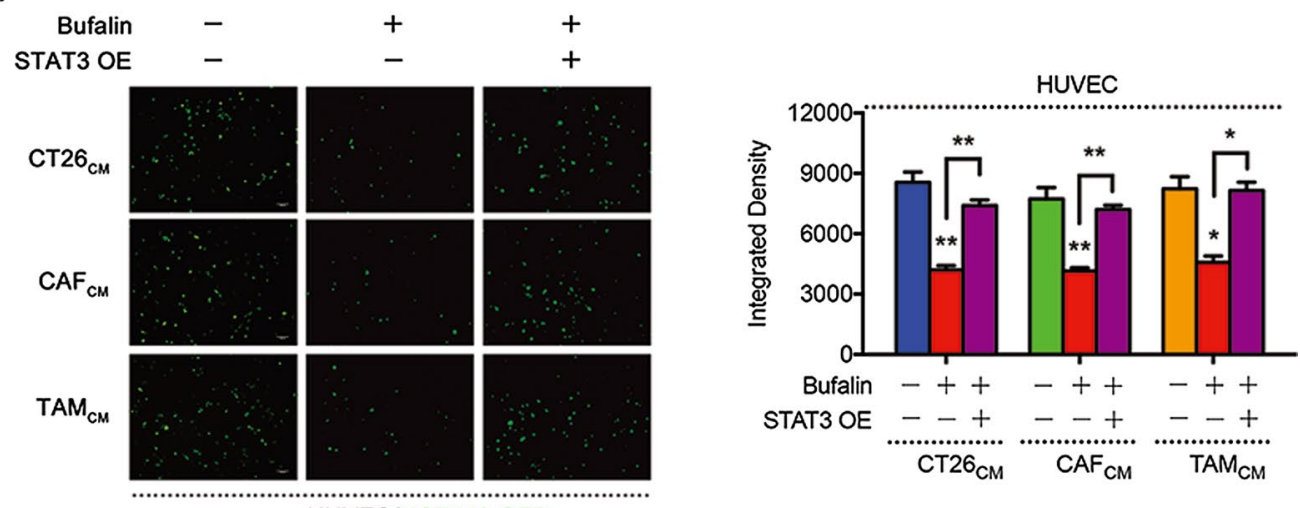

Fig. 3 Bufalin suppresses TME-mediated angiogenesis by the STAT3 signalling pathway. Tube formation (a), migration (b) and adhesion (c) of HUVECS after treatment with TME-CMs and BU with or without the STAT3-OE plasmid. ${ }^{*} \mathrm{P}<0.05,{ }^{* *} \mathrm{P}<0.01,{ }^{* * *} \mathrm{P}<0.001$. Data are shown as mean s.e.m. BU, bufalin

(See figure on next page.)

Fig. 4 Bufalin suppresses TME-mediated angiogenesis by directly affecting vascular endothelial cells. Tube formation (a), migration (b), and adhesion (c) of HUVECs treated with TME-CMs and TME + BU-CMs for $24 \mathrm{~h}$. $\mathbf{d}-\mathbf{f}$ WB showing the protein expression of p-STAT3 and STAT3 in HUVECS treated with different TME-CMs and TME + BU-CMs, membranes were stripped and re-probed with total $\beta$-actin as a control. N.S. indicates no significant difference between the two groups, $P>0.05$. Data are shown as mean s.e.m. BU, bufalin 
A

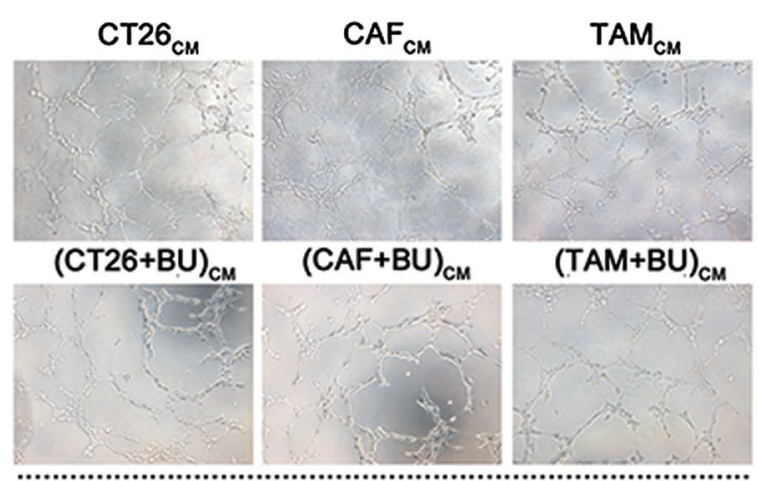

HUVEC

B

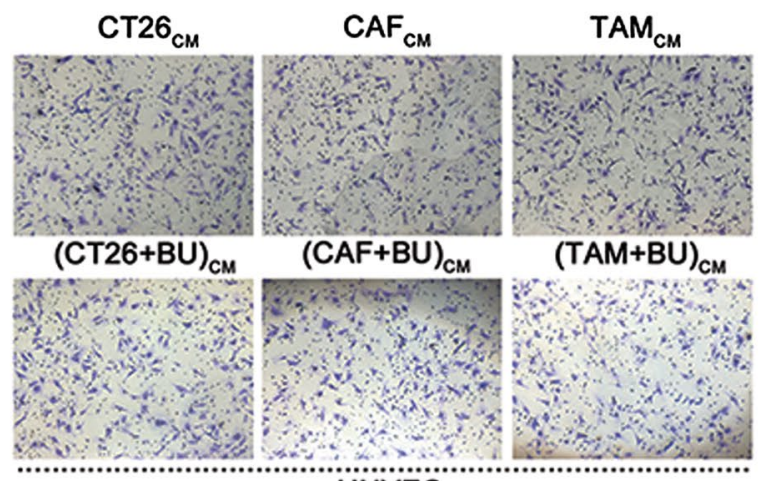

C

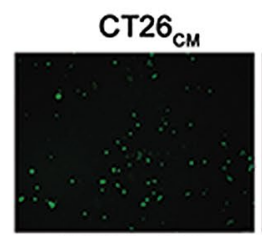

$(\mathrm{CT} 26+\mathrm{BU})_{\mathrm{CM}}$

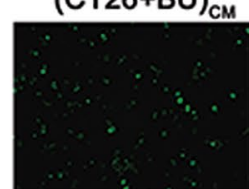

HUVEC

$\mathrm{CAF}_{\mathrm{CM}}$

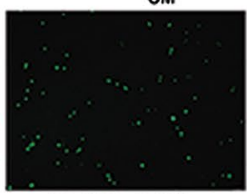

$(\mathrm{CAF}+\mathrm{BU})_{\mathrm{CM}}$

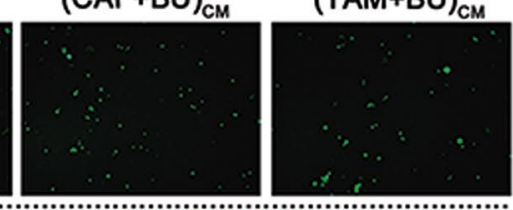

HUVEC/HCT116-GFP
$\mathrm{TAM}_{\mathrm{CM}}$

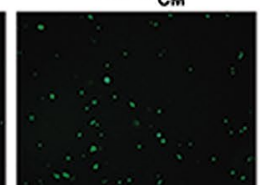

$(T A M+B U)_{c M}$
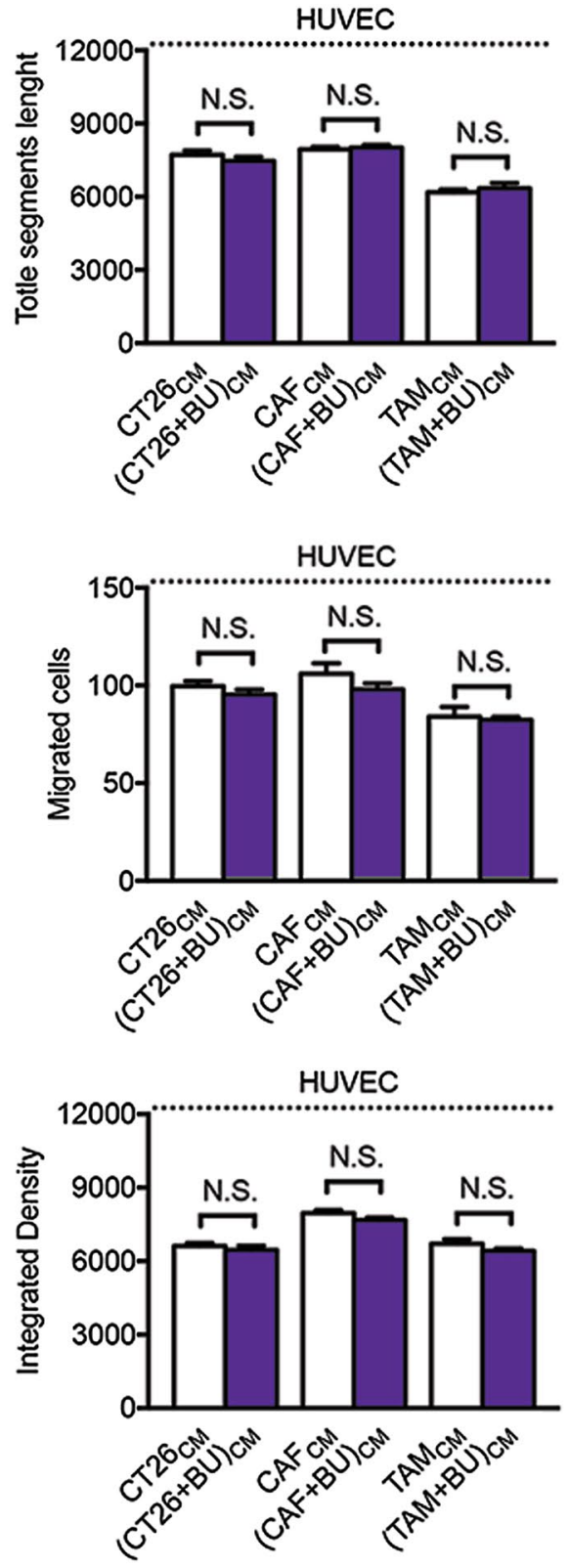

$\mathbf{F}$

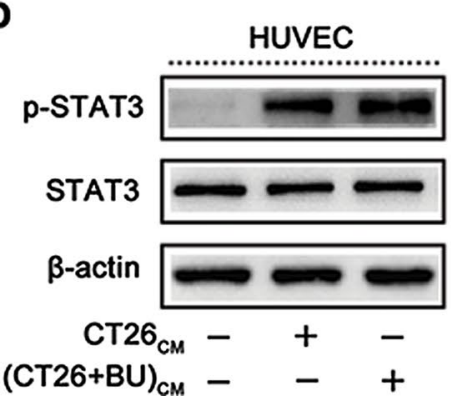

E

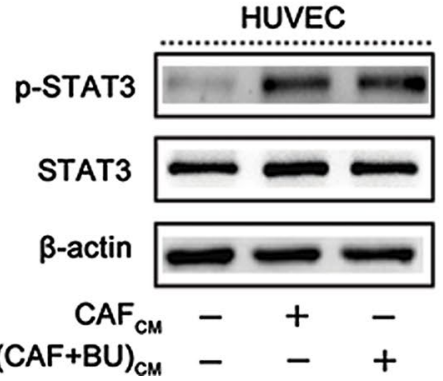

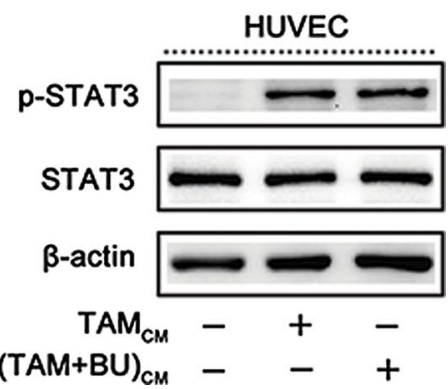

Fig. 4 (See legend on previous page.) 


\section{Immunohistochemistry (IHC)}

The tissues were fixed in $10 \%$ formalin, embedded in paraffin, and then sectioned (5 mm thick). IHC of CD31 was performed as follows. The slides were dewaxed and incubated with a $3 \%$ aqueous solution of $\mathrm{H}_{2} \mathrm{O}_{2}$ for $10 \mathrm{~min}$ to quench endogenous peroxidase activity. The heatinduced antigen recovery method was used to detect the antigen. Tissues were incubated with 5\% BSA for $30 \mathrm{~min}$ at room temperature and then incubated with the primary antibody in PBS at $4{ }^{\circ} \mathrm{C}$ overnight (CD31, Abcam, ab28364, rabbit IgG) and (Ki67, Abcam, ab15580, rabbit IgG). The appropriate secondary antibody was used to apply the indirect avidin-biotin-peroxidase method at room temperature for $30 \mathrm{~min}$. An EnVision (K4007, Dako) signal enhancement system was used to develop the bound antibodies. The sections were stained with Harris haematoxylin, dehydrated and fixed. For quantification, 30 random images $(400 \times)$ were captured with a microscope (Leica, Wetzlar, Germany).

\section{ELISA}

VEGF in HUVEC culture supernatants was evaluated by a Human VEGF Quantikine ELISA Kit (R\&D, Minnesota, USA) according to the manufacturer's protocol. VEGF in serum was evaluated by a Mouse VEGF Quantikine ELISA Kit (R\&D, Minnesota, USA) according to the manufacturer's protocol.

\section{Statistical analysis}

All statistical analyses were performed using Excel 2016, GraphPad Prism 8, and R (v.8.0.1) software. Each experimental value is expressed as the mean $\pm \mathrm{SD}$. An unpaired t-test was performed for comparisons between two groups and one-way analysis of variance (ANOVA) was applied for pairwise comparisons among multiple groups with Tukey's post hoc test, and significance was accepted at ${ }^{*} \mathrm{p}<0.05,{ }^{* *} \mathrm{p}<0.01$ and ${ }^{* * * *} \mathrm{p}<0.001$

\section{Results}

\section{Bufalin suppresses angiogenesis induced by cells} in the tumour microenvironment

To clarify the effects of bufalin on angiogenesis caused by TME cells, we collected the supernatants of CT26 cells, CAFs and TAMs as TME-conditioned media (CMs). Furthermore, we selected a low concentration ( $\mathrm{IC}_{15}$, $10 \mathrm{nM}$ ) of bufalin to treat HUVECs for $24 \mathrm{~h}$ (Fig. 1b).
We examined the mechanism by which bufalin inhibits angiogenesis and affects the occurrence and development of colorectal cancer. The cell proliferation experiment showed that the TME had no significant effect on HUVEC proliferation after treatment with TME-CMs (CT26-CM, CAF-CM and TAM-CM) for $24 \mathrm{~h}$ (Fig. 1c). The effects of bufalin on TME-mediated angiogenesis was determined by HUVEC tube formation, migration and adhesion experiments, and the results showed that bufalin inhibited angiogenesis induced by TME cells (Fig. 1d-f).

\section{Bufalin suppresses TME-mediated angiogenesis by inhibiting angiogenic factors}

To determine the mechanism by which bufalin inhibits TME-mediated angiogenesis, we observed the expression of the angiogenesis-related and migratory factors VEGF and PDGFA and the vascular adhesion genes E-selectin and P-selectin in HUVECs treated with or without bufalin in combination with TME-CMs by quantitative PCR. The results showed that bufalin could significantly downregulate the expression of these genes in HUVECs that were increased by the TME (Fig. $2 \mathrm{a}-\mathrm{c}$ ).

Previous studies have shown that the STAT3 signalling pathway plays a critical role in angiogenesis by inducing angiogenic factors, such as VEGFs, PDGFs and other angiogenic factors $[20,21]$. In our study, the WB experiment showed that bufalin could directly decease STAT3 phosphorylation in HUVECs activated by the TME (Fig. $2 \mathrm{~d}-\mathrm{f}$ ), and the results of the immunofluorescence experiment confirmed these findings (Fig. 2g). In addition, we found that bufalin could inhibit VEGF expression by WB (Fig. 2d-f) and ELISA (Fig. 2h-j). Taken together, these results suggest that bufalin could decrease STAT3 phosphorylation to downregulate angiogenic factor expression induced by the TME in vascular endothelial cells.

\section{Bufalin suppresses TME-mediated angiogenesis by the STAT3 signalling pathway}

To investigate whether the STAT3 signalling pathway is a key factor by which bufalin inhibits TME-mediated angiogenesis, we constructed a STAT3-overexpression (STAT3-OE) plasmid. STAT3 expression was confirmed by WB (Additional file 2: Fig. S2a) and qPCR (Additional file 2: Fig. S2b). We found that the STAT3-OE plasmid

\footnotetext{
(See figure on next page.)

Fig. 5 Bufalin inhibits CRC cell growth via an antiangiogenic mechanism in vivo. a Scheme and schedule of imaging and treatments. $\mathbf{b}$ Tumour volumes from day 0 to day 28. c Tumour growth was visualized by an in vivo imaging system from day 7 to day 28 . d Tumour weights and images. e IHC analysis of CD31 and Ki67 in tumours. $\mathbf{f}$ VEGF expression level in serum. $\mathbf{g}$ Immunofluorescence analysis of CD31 and p-STAT3 in tumours. ${ }^{* *} \mathrm{P}<0.01,{ }^{* * *} \mathrm{P}<0.001$. Data are shown as mean s.e.m. IHC, immunohistochemistry
} 
A

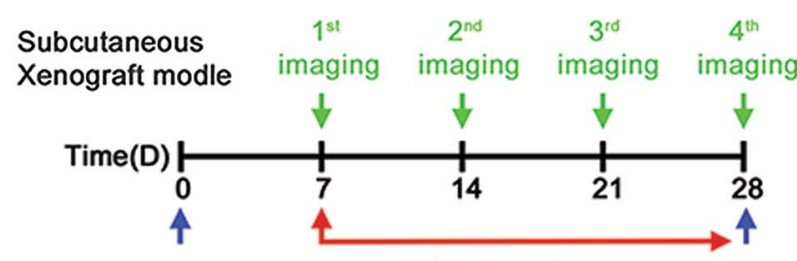

Subcutaneous inoculated Bufalin $(1 \mathrm{mg} / \mathrm{kg})$ by i.p. Sacrifice with $2 \times 10^{6} \mathrm{CT} 26$ cells once every two days

C

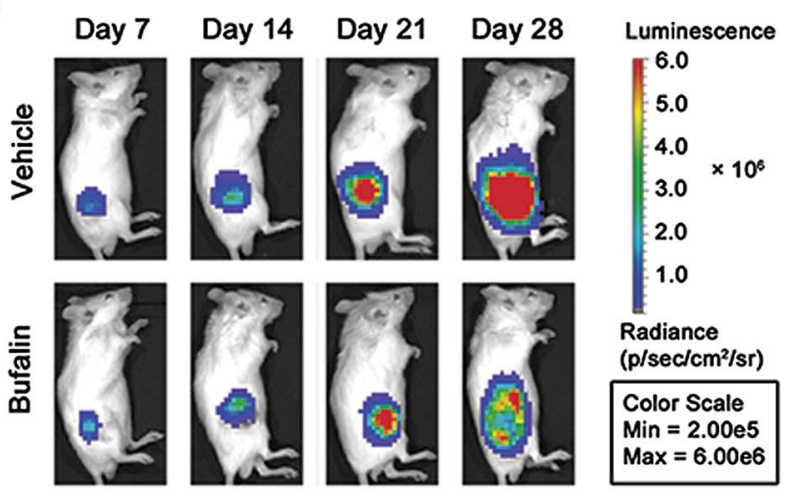

E

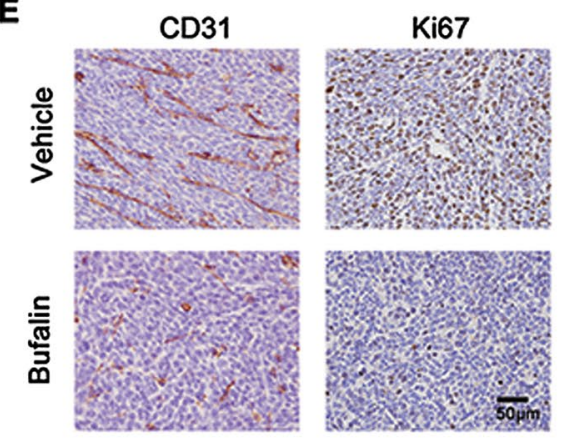

B

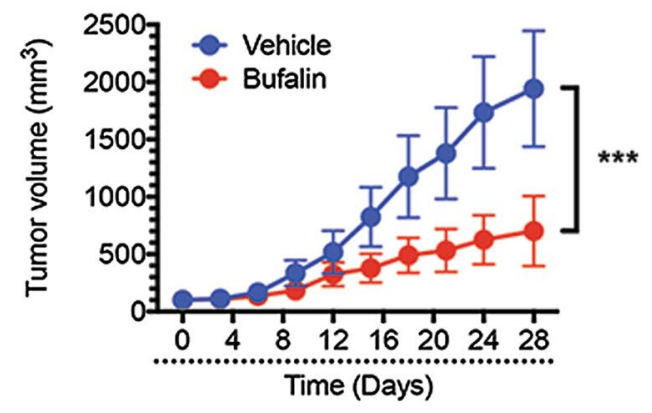

D

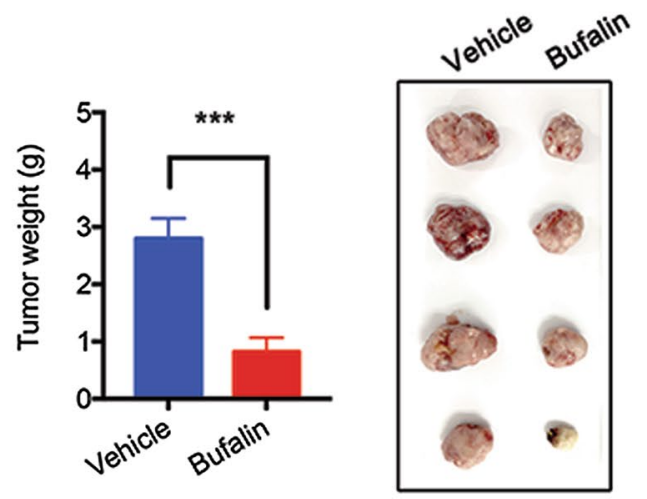

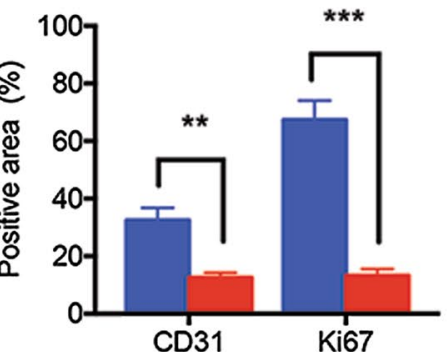

$\mathbf{F}$

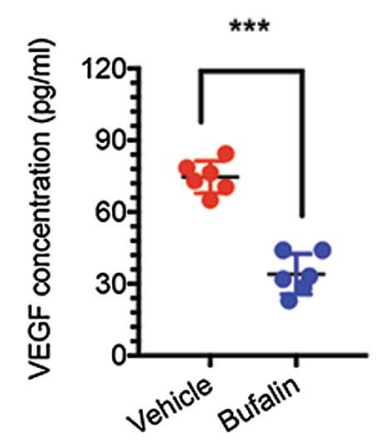

$\mathbf{G}$
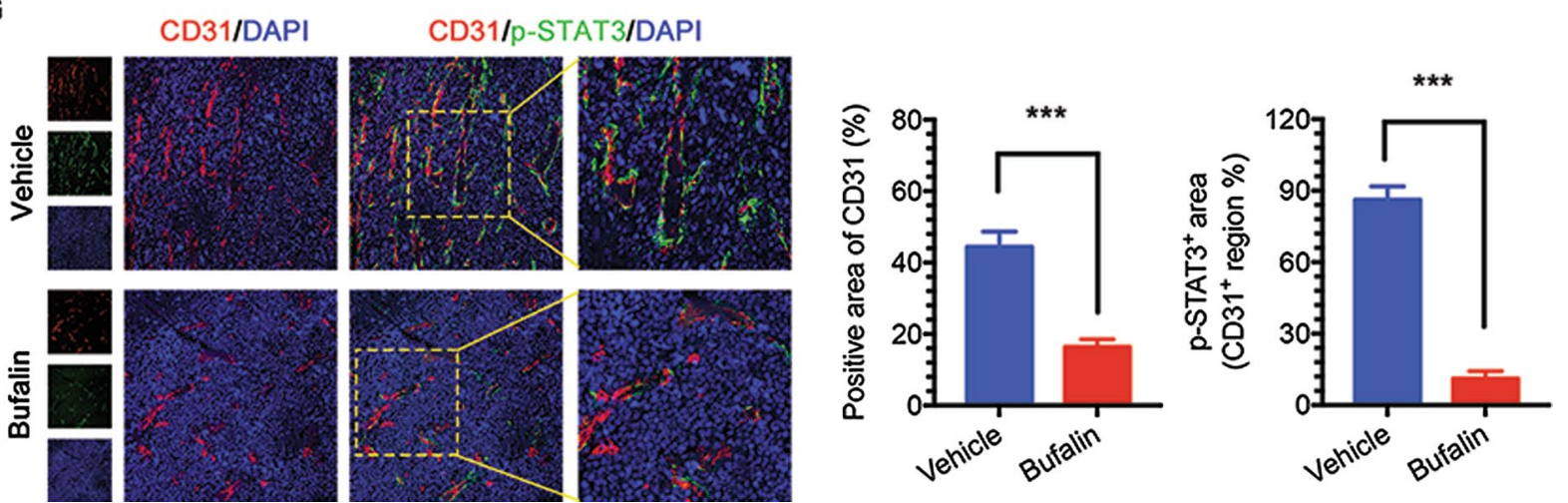

Fig. 5 (See legend on previous page.) 
prevented bufalin-mediated inhibition of HUVEC tube formation (Fig. 3a), migration (Fig. 3b) and adhesion (Fig. 3c) induced by the TME. These results suggest that bufalin inhibits TME-induced angiogenesis through the STAT3 signalling pathway and that STAT3 plays an important role in this process.

Bufalin suppresses TME-mediated angiogenesis by directly affecting vascular endothelial cells but not altering tumour microenvironment cells

Next, we determined whether bufalin also indirectly affects endothelial cells by altering TME cells. We first treated TME cells (CT26 cells, CAFs and TAMs) with $10 \mathrm{nM}$ bufalin for $24 \mathrm{~h}$, replaced the medium with serumfree medium and collected the cell supernatant after an additional $24 \mathrm{~h}$ of incubation for use as (TME + BU)-CM, which was then used to treat HUVECs for $24 \mathrm{~h}$. Then, HUVEC tube formation (Fig. 4a), migration (Fig. 4b) and adhesion (Fig. 4c) were analysed. The results showed that bufalin did not affect vascular endothelial cells by affecting TME cells. The WB results also proved that there were no significant differences in the increase in phosphorylated STAT3 levels in HUVECs induced by (TME + BU)-CMs and TME-CMs (Fig. 4d-f). Taken together, these results suggest that bufalin suppresses TME-mediated angiogenesis by directly affecting vascular endothelial cells but not altering TME cells.

\section{Bufalin inhibits CRC cell growth via an antiangiogenic mechanism in vivo}

To determine the effects of bufalin in vivo, a CRC cell xenograft model was established by using CT26 cells expressing luciferase (CT26-LUC). The schedule is shown in Fig. 5a. All mice started treatment 1 week after xenotransplantation. The volumes of the subcutaneous tumours (Fig. 5b) and in vivo imaging (Fig. 5c, Additional file 3: Fig. S3b) were recorded during the treatment cycle (3 weeks). Subcutaneous tumours in the two groups of mice were weighed and photographed (Fig. 5d). The results showed that bufalin significantly inhibited tumour growth compared with vehicle without affecting animal body weight (Additional file 3: Fig. S3a), suggesting that bufalin had no serious toxic effects on the body. To further confirm the antiangiogenic effects obtained in vitro, we used IHC to evaluate the expression of CD31 and Ki67 in the tumours. The results of IHC showed a reduction in proliferation and subcutaneous tumour blood vessels in the bufalin group (Fig. 5e). Next, we measured the serum VEGF levels in the two groups of mice by ELISA, and the results showed that the serum VEGF levels in the bufalin group were significantly lower than those in the vehicle group (Fig. 5f). Moreover, we examined the activation of vascular STAT3 in solid tumours. The immunofluorescence results showed that the number of blood vessels in subcutaneous tumours and the proportion of activated STAT3-positive blood vessels in the bufalin group were significantly lower than those in the vehicle group (Fig. 5g). These data indicate that bufalin inhibited angiogenesis by targeting the activation of STAT3 in tumour blood vessels, thereby inhibiting tumour growth in a CRC cell xenograft model.

\section{Bufalin inhibits CRC cell metastasis via an antiangiogenic mechanism in vivo}

Cancer metastasis remains a major challenge for the successful management of malignant diseases. The liver is the main site of metastatic disease and a major cause of death from colorectal cancer [22]. To investigate the antiangiogenic effects of bufalin on the inhibition of CRC metastasis in vivo, we established a liver metastasis model (Fig. 6a), and the progression of tumour metastasis was observed by an in vivo imaging system from Day 7 to Day 21 (Fig. 6b, Additional file 4: Fig. S4b). The in vivo imaging results showed that after 1 week of bufalin treatment, bufalin began to inhibit liver metastasis compared to the vehicle group, and until the mice were sacrificed on Day 21, bufalin significantly inhibited liver metastases by more than $50 \%$ compared to vehicle treatment without affecting animal body weight (Additional file 4: Fig. S4a). Metastatic foci of considerable sizes were visible in the livers of mice treated with vehicle. Haematoxylin-eosinstained liver sections were examined under a microscope, and as expected, the formation of metastases in the liver was reduced by approximately $80 \%$ after bufalin treatment (Fig. 6c, d). The IHC results showed a reduction in the number of blood vessels in the spleen and liver metastases in the bufalin group (Fig. 6e). Similarly, mice treated with bufalin had significantly lower serum VEGF levels than mice treated with vehicle (Fig. 6f). Consistent with the subcutaneous tumours, the immunofluorescence results showed that the number of blood vessels in the liver tumours and the number of p-STAT3-positive

(See figure on next page.)

Fig. 6 Bufalin inhibits CRC cell metastasis via an antiangiogenic mechanism in vivo. a Scheme and schedule of imaging and treatments. b Tumour metastasis was visualized by an in vivo imaging system from day 7 to day 21 . c Representative images of liver and H\&E-stained liver tissue. $\mathbf{d}$ Tumour number and area in liver. e IHC analysis of CD31 in spleen and liver tissue. $\mathbf{f}$ VEGF expression level in serum. $\mathbf{g}$ Immunofluorescence analysis of CD31 and $\mathrm{p}$-STAT3 in liver. ${ }^{* * P}<0.01,{ }^{* *} \mathrm{P}<0.001$. Data are shown as mean s.e.m. $\mathrm{IHC}$, immunohistochemistry 


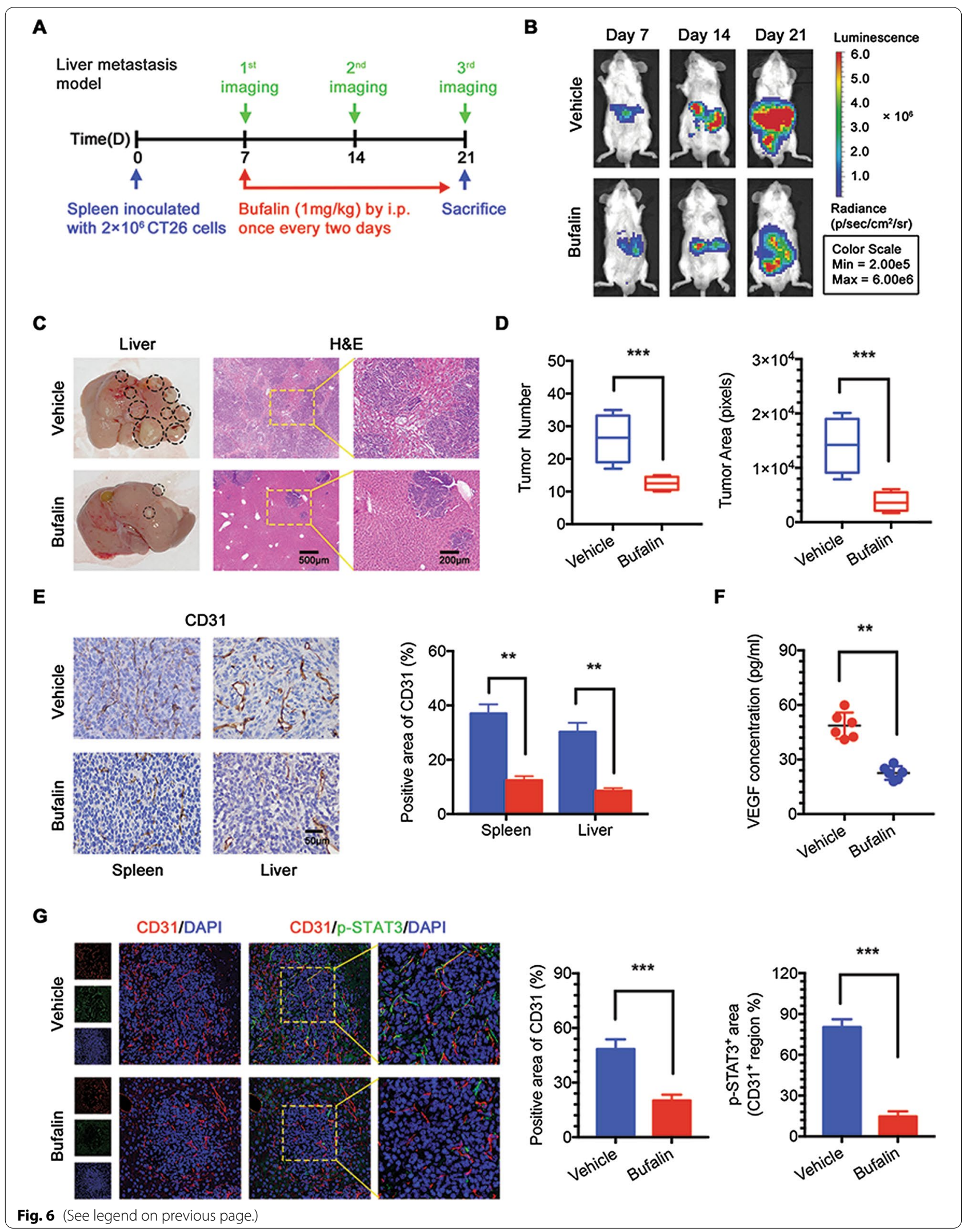




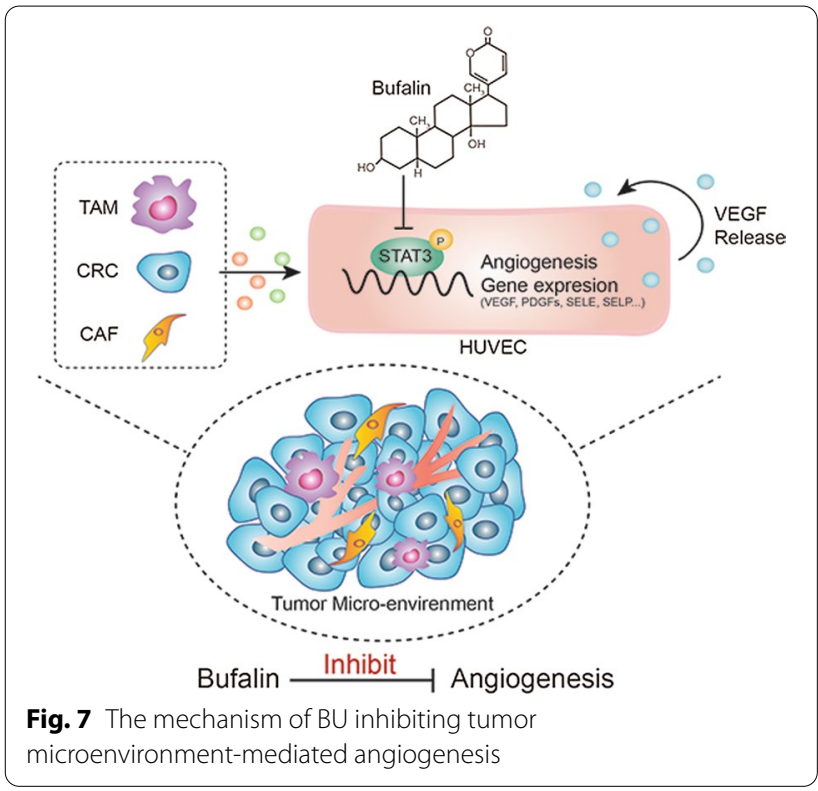

blood vessels significantly decreased after bufalin treatment (Fig. 6g). Interestingly, STAT3 in endothelial cells was activated only at the tumour site, while it was rarely activated in normal liver tissues. This result further suggests that bufalin inhibits liver metastasis by targeting STAT3 in tumour blood vessels not only in primary tumours but also in metastatic tumours (Fig. 6g).

\section{Discussion}

Accumulating evidence has verified that angiogenesis plays a critical role in tumour progression and that inhibiting angiogenesis is a promising strategy for tumour treatment [23, 24]. Angiogenic programming in neoplastic tissue is a multidimensional process regulated by tumour cells in conjunction with various tumour-associated stromal cells, as well as the TME [10, 25-27]. We found that bufalin could reverse angiogenesis mediated by the TME.

Antiangiogenic therapy is an important strategy for the treatment of CRC. Previous studies have reported that bufalin can synergistically enhance the antiangiogenic effects of sorafenib via AKT/VEGF signaling [16]. We found that bufalin could inhibit the tube formation, adhesion and migration of HUVECs mediated by CAFs, TAMs and tumour cells by inhibiting the activation of HUVEC STAT3 and thereby decreasing the expression of VEGF, PDGFA, E-selectin, and P-selectin. Similarly, we established a subcutaneous tumour model and a liver metastasis model in vivo, and we found that bufalin inhibited the growth and metastasis of CRC by significantly reducing the number of blood vessels and amount of STAT3 phosphorylation in vascular endothelial cells.
In addition, the serum concentration of VEGF after bufalin treatment was significantly reduced. These findings indicate that bufalin targets the STAT3 signalling pathway to reduce TME-mediated angiogenesis.

STAT3 is a transcription factor that regulates various kinds of cellular events, including differentiation, apoptosis and proliferation [28]. Previous studies have shown that STAT3 activation promotes tumour angiogenesis by increasing VEGF expression [29, 30]. Intercellular communication between the TME and vascular endothelial cells is promoted by STAT3 [31]. Notably, STAT3 is an important target of bufalin, and bufalin can inhibit STAT3 activity. Moreover, we found that STAT3 overexpression could reverse the inhibitory effects of bufalin on angiogenesis. Collectively, we propose a model in which bufalin reduces the expression of angiogenic genes by inhibiting the phosphorylation of STAT3 on endothelial cells, thereby antagonizing the proangiogenic effects of the tumour microenvironment (Fig. 7).

More interestingly, we found that bufalin could suppress TME-mediated angiogenesis. Furthermore, we treated CAFs, TAMs and tumour cells with bufalin and then used the conditioned cell supernatants to treat HUVECs and found no effects on tube formation, migration or adhesion, which ruled out the direct effects of bufalin on TME cells. Notably, compared to other previous antitumour studies on bufalin [32, 33], we chose a lower concentration of bufalin and a shorter treatment time for both the in vitro and in vivo experiments. These results suggest a new mechanism by which low concentrations of bufalin affect TME-mediated angiogenesis; direct action on the STAT3 signalling pathway on vascular endothelial cells but not TME cells, and this effect is characterized by low toxicity and high efficiency.

In summary, our results show that the TME promotes tumour angiogenesis by activating STAT3 in vascular endothelial cells and that bufalin can precisely inhibit angiogenesis by targeting STAT3. Through our research, we have enriched the understanding of the antitumour effects of bufalin, which can indirectly inhibit TMEmediated angiogenesis. In the future, bufalin may be developed as a new type of antiangiogenic auxiliary drug.

\section{Conclusions}

In summary, bufalin suppresses tumour microenvironment-mediated angiogenesis by inhibiting the STAT3 signalling pathway. The tumour microenvironment promotes tumour angiogenesis by activating STAT3 in vascular endothelial cells, and bufalin can precisely inhibit angiogenesis by targeting STAT3. Thus, bufalin may be used as a new antiangiogenic adjuvant therapy in the treatment of colorectal cancer. 


\section{Abbreviations}

STAT3: Signal transducer and activator of transcription 3; TME: Tumour microenvironment; HUVECs: Human umbilical vein endothelial cells; CRC: Colorectal cancer; CAF: Cancer-associated fibroblast; TAM: Tumour-associated macrophage; BU: Bufalin; CM: Conditioned medium; WB: Western blot; PCR: Polymerase chain reaction; IHC: Immunohistochemistry; Elisa: Enzyme linked immunosorbent assay.

\section{Supplementary Information}

The online version contains supplementary material available at https://doi. org/10.1186/s12967-021-03058-z.

Additional file 1: Figure S1. Confirmation of CT26, CAF and TAM. a Photos of CT26 cells and CAFs. b Tumour cell and CAF marker proteins were determined using WB. c Morphological changes of TAM. d TAM determined by Flow cytometry.

Additional file 2: Figure S2. Effect of Plasmids transfection. HUVECs STAT3 expression was confirmed by WB (a) and quantitative PCR (b).

Additional file 3: Figure S3. a Body weight of subcutaneous tumor model mice. b Quantitative analysis of fluorescence intensity in subcutaneous tumor model mice. Each point represents an independent mouse.

Additional file 4: Figure S4. a Body weight of liver metastasis model mice. b Quantitative analysis of fluorescence intensity in liver metastasis model. Each point represents an independent mouse.

\section{Acknowledgements}

Not applicable.

\section{Authors' contributions}

$K X, X L$, and $P Y$ conceived and directed the project. $K X$ designed the experiments. KF, YW, CW, RZ, and MS carried out the experiments. $K X, K F$, and $Y Z$ conducted the data analysis and interpreted the results. $K F, K X, Y Z, X L$, and PY wrote and edited the paper. All authors read and approved the final manuscript.

\section{Funding}

This project was sponsored by the Science and technology innovation project of Putuo District Health system (ptkwws201905), the Budget project of Shanghai University of Traditional Chinese Medicine (2019LK039) and the Natural Science Foundation of Shanghai (20ZR1450500,19ZR1413800). This project was also sponsored by the National Nature Science Foundation of China (81873137).

\section{Availability of data and materials}

The datasets during and/or analysed during the current study available from the corresponding author on reasonable request.

\section{Declarations}

\section{Ethics approval and consent to participate}

Not applicable.

\section{Consent for publication}

Not applicable.

\section{Competing interests}

The authors declare that they have no conflict of interest.

\section{Author details}

${ }^{1}$ Putuo Hospital, Shanghai University of Traditional Chinese Medicine, Shanghai 200062, China. ${ }^{2}$ Institute of Translational Medicine, Shanghai University, Shanghai 200444, China. ${ }^{3}$ Interventional Cancer Institute of Chinese Integrative Medicine, Shanghai University of Traditional Chinese Medicine, Shanghai 200062, China. ${ }^{4}$ State Key Laboratory of Bioreactor Engineering \& Shanghai Key Laboratory of New Drug Design, School of Pharmacy, East China University of Science and Technology, 130 Meilong Rd, Shanghai 200237,
China. ${ }^{5}$ Shanghai Putuo Central School of Clinical Medicine, Anhui Medical University, Hefei 230032, China. ${ }^{6}$ Wenzhou Institute of Shanghai University, Wenzhou 325000, China.

Received: 28 April 2021 Accepted: 26 August 2021

Published online: 08 September 2021

\section{References}

1. Bray F, Ferlay J, Soerjomataram I, Siegel RL, Torre LA, Jemal A. Global cancer statistics 2018: GLOBOCAN estimates of incidence and mortality worldwide for 36 cancers in 185 countries. CA Cancer J Clin. 2018;68(6):394-424

2. Kuczynski EA, Vermeulen PB, Pezzella F, Kerbel RS, Reynolds AR. Vessel co-option in cancer. Nat Rev Clin Oncol. 2019;16(8):469-93.

3. Kobayashi H, Enomoto A, Woods SL, Burt AD, Takahashi M, Worthley DL. Cancer-associated fibroblasts in gastrointestinal cancer. Nat Rev Gastroenterol Hepatol. 2019;16(5):282-95.

4. Battaglin F, Puccini A, Intini R, Schirripa M, Ferro A, Bergamo F, et al. The role of tumor angiogenesis as a therapeutic target in colorectal cancer. Expert Rev Anticancer Ther. 2018;18(3):251-66.

5. Mesange P, Bouygues A, Ferrand N, Sabbah M, Escargueil A, Savina $A$, et al. Combinations of bevacizumab and erlotinib show activity in colorectal cancer independent of RAS status. Clin Cancer Res. 2018;24(11):2548-58

6. Tournigand C, Chibaudel B, Samson B, Scheithauer W, Vernerey D, Mésange $P$, et al. Bevacizumab with or without erlotinib as maintenance therapy in patients with metastatic colorectal cancer (GERCOR DREAM; OPTIMOX3): a randomised, open-label, phase 3 trial. Lancet Oncol. 2015;16(15):1493-505.

7. Ranieri G, Patruno R, Ruggieri E, Montemurro S, Valerio P, Ribatti D. Vascular endothelial growth factor (VEGF) as a target of bevacizumab in cancer: from the biology to the clinic. Curr Med Chem. 2006;13(16):1845-57.

8. Palma MD, Biziato D, Petrova TV. Microenvironmental regulation of tumour angiogenesis. Nat Rev Cancer. 2017;17(8):457-74.

9. Jiang $X$, Wang J, Deng X, Xiong F, Zhang S, Gong Z, et al. The role of microenvironment in tumor angiogenesis. J Exp Clin Cancer Res. 2020;39(1):75.

10. Unterleuthner D, Neuhold P, Schwarz K, Janker L, Neuditschko B, Nivarthi $H$. Cancer-associated fibroblast-derived WNT2 increases tumor angiogenesis in colon cancer. Angiogenesis. 2019;23(2):159-77.

11. Don-Doncow N, Marginean F, Coleman I, Nelson PS, Ehrnstrom R, Krzyzanowska A, et al. Expression of STAT3 in prostate cancer metastases. Eur Urol. 2017;71(3):313-6.

12. Pan Y-M, Wang C-G, Zhu M, Xing R, Cui J-T, Li W-M, et al. STAT3 signaling drives $\mathrm{EZH} 2$ transcriptional activation and mediates poor prognosis in gastric cancer. Mol Cancer. 2016:15(1):79.

13. Du Y-e, Tu G, Yang G, Li G, Yang D, Lang L, et al. MiR-205/YAP1 in activated fibroblasts of breast tumor promotes VEGF-independent angiogenesis through STAT3 signaling. Theranostics. 2017;7(16):3972-88

14. Zhan Y, Qiu Y, Wang H, Wang Z, Xu J, Fan G, et al. Bufalin reverses multidrug resistance by regulating stemness through the CD133/ nuclear factor-kB/MDR1 pathway in colorectal cancer. Cancer Sci. 2020;111(5):1619-30.

15. Huang WW, Yang JS, Pai SJ, Wu PP, Chang SJ, Chueh FS, et al. Bufalin induces $\mathrm{G} 0 / \mathrm{G} 1$ phase arrest through inhibiting the levels of cyclin D, cyclin E, CDK2 and CDK4, and triggers apoptosis via mitochondrial signaling pathway in T24 human bladder cancer cells. Mutat Res. 2012;732(1-2):26-33

16. Wang H, Zhang C, Ning Z, Xu L, Zhu X, Meng Z. Bufalin enhances anti-angiogenic effect of sorafenib via AKT/NEGF signaling. Int J Oncol. 2016;48(3):1229-41.

17. Wu X, Tian F, Su M, Wu M, Huang Y, Hu L, et al. BF211, a derivative of bufalin, enhances the cytocidal effects in multiple myeloma cells by inhibiting the IL-6/JAK2/STAT3 pathway. Int Immunopharmacol. 2018;64:24-32.

18. Sun J, Xu K, Qiu Y, Gao H, Xu J, Tang Q, et al. Bufalin reverses acquired drug resistance by inhibiting stemness in colorectal cancer cells. Oncol Rep. 2017;38(3):1420-30 
19. Yin P, Wang Y, Qiu Y, Hou L, Liu X, Qin J, et al. Bufalin-loaded mPEG-PLGAPLL-cRGD nanoparticles: preparation, cellular uptake, tissue distribution, and anticancer activity. Int J Nanomedicine. 2012;7:3961-9.

20. Liu J, Deng W, Chen L, Li Y, Wu L, Ma S, et al. Inhibition of JAK2/STAT3 reduces tumor-induced angiogenesis and myeloid-derived suppressor cells in head and neck cancer. Mol Carcinog. 2018;57(3):429-39.

21. Liang L, Hui K, Hu C, Wen Y, Yang S, Zhu P, et al. Autophagy inhibition potentiates the anti-angiogenic property of multikinase inhibitor anlotinib through JAK2/STAT3/VEGFA signaling in non-small cell lung cancer cells. J Exp Clin Cancer Res. 2019;38(1):71.

22. Brodt P. Role of the microenvironment in liver metastasis: from pre- to prometastatic niches. Clin Cancer Res. 2016;22(24):5971-82.

23. Cao J, Liu X, Yang Y, Wei B, Li Q, Mao G, et al. Decylubiquinone suppresses breast cancer growth and metastasis by inhibiting angiogenesis via the ROS/p53/ BAl1 signaling pathway. Angiogenesis. 2020;23(3):325-38.

24. Dai L, Cui $X$, Zhang $X$, Cheng $L$, Liu $Y$, Yang $Y$, et al. SARI inhibits angiogenesis and tumour growth of human colon cancer through directly targeting ceruloplasmin. Nat Commun. 2016;29(7):11996.

25. Jetten N, Verbruggen S, Gijbels M, Post M, Winther MD, Donners M. Antiinflammatory $\mathrm{M} 2$, but not pro-inflammatory $\mathrm{M} 1$ macrophages promote angiogenesis in vivo. Angiogenesis. 2014;17(1):109-18.

26. Britto D, Wyroba B, Chen W, Lockwood R, Tran K, Shepherd P, et al. Macrophages enhance Vegfa-driven angiogenesis in an embryonic zebrafish tumour xenograft model. Dis Model Mech. 2018;11(12):dmm035998.

27. Zhang T, Liu L, Lai W, Zeng Y, Xu H, Lan Q, et al. Interaction with tumorassociated macrophages promotes PRL3induced invasion of colorectal cancer cells via MAPK pathway induced EMT and NFkappaB signalling induced angiogenesis. Oncol Rep. 2019;41(5):2790-802.

28. Yu H, Lee H, Herrmann A, Buettner R, Jove R. Revisiting STAT3 signalling in cancer: new and unexpected biological functions. Nat Rev Cancer. 2014;14(11):736-46

29. Wei D, Le X, Zheng L, Wang L, Frey J, Gao A, et al. Stat3 activation regulates the expression of vascular endothelial growth factor and human pancreatic cancer angiogenesis and metastasis. Oncogene. 2003;22(3):319-29.

30. Niu G, Wright KL, Huang M, Song L, Haura E, Turkson J, et al. Constitutive Stat3 activity up-regulates VEGF expression and tumour angiogenesis. Oncogene. 2002;21(13):2000-8.

31. Kujawski M, Kortylewski M, Lee H, Herrmann A, Kay H, Yu H. Stat3 mediates myeloid cell-dependent tumor angiogenesis in mice. J Clin Invest. 2008;118(10):3367-77.

32. Zhang Y, Dong Y, Melkus M, Yin S, Tang S, Jiang P, et al. Role of P53-senescence induction in suppression of LNCaP prostate cancer growth by cardiotonic compound bufalin. Mol Cancer Ther. 2018;17(11):2341-52.

33. Liu X, Zhou Y, Peng J, Xie B, Shou Q, Wang J. Silencing c-myc enhances the antitumor activity of bufalin by suppressing the HIF-1alpha/SDF-1/ CXCR4 pathway in pancreatic cancer cells. Front Pharmacol. 2020;11:495.

\section{Publisher's Note}

Springer Nature remains neutral with regard to jurisdictional claims in published maps and institutional affiliations.
Ready to submit your research? Choose BMC and benefit from:

- fast, convenient online submission

- thorough peer review by experienced researchers in your field

- rapid publication on acceptance

- support for research data, including large and complex data types

- gold Open Access which fosters wider collaboration and increased citations

- maximum visibility for your research: over $100 \mathrm{M}$ website views per year

At BMC, research is always in progress.

Learn more biomedcentral.com/submissions 